\title{
Effect of Nordic Walking on Depression and Physical Function in the Elderly with High-Risk of Depression
}

\author{
Tae-Geun An, PT $\cdot$ Han-Suk Lee, PT, $\mathrm{PhD}^{1 \dagger} \cdot$ Sun-Wook Park, PT, PhD ${ }^{2} \cdot$ Hee-Chang Seon, PT, BS
}

Su Jeong Jungang Senior Welfare Center, ${ }^{1}$ Department of Physical Therapy, Eulji university,

${ }^{2}$ Seoul Sam Sung Medical Center

Received: August 17, 2020 / Revised: August 18, 2020 / Accepted: September 3, 2020

(C) 2020 J Korean Soc Phys Med

\section{| Abstract |}

PURPOSE: This study examined the effects of Nordic walking on depression and the physical function of elderly patients with a high risk of depression.

METHODS: This study was a blinded randomized allocation study; 32 elderly were assigned to a Nordic walking group $(\mathrm{n}=17)$, consisting of 60 min Nordic walking (including warming up $5 \mathrm{~min}$, warming down $5 \mathrm{~min}$, and Nordic walking $50 \mathrm{~min}$ ) two days per week for 12 weeks and general leisure group $(n=15)$, consisting of 60 min leisure program community center. The pre and post 12-week program, depression test, muscle strength (including grip test, and $30 \mathrm{sec}$ sit to stand), and balance (including Functional Reach test, and One Leg Standing test) were measured. A Mann-Whitney U test was used to compare within the group, and a Wilcoxon signed-rank test was used to compare

$\dagger$ Corresponding Author : Han-Suk Lee leehansuk21@hanmail.net, https://orcid.org/0000-0002-9336-0894 This is an Open Access article distributed under the terms of the Creative Commons Attribution Non-Commercial License (http://creativecommons.org/licenses/by-nc/3.0) which permits unrestricted non-commercial use, distribution, and reproduction in any medium, provided the original work is properly cited. between the groups.

RESULTS: After 12 weeks, only the Nordic walking group showed significant improvement in depression, muscle strength, and balance $(\mathrm{p}<.05)$. In the general leisure group, however, the left grip strength and Functional Reach Test (FRT) showed a significant decrease. The Nordic walking program was better than the general leisure group, and a significant difference was observed in depression, muscle strength, and balance between the two groups $(\mathrm{p}<.05)$.

CONCLUSION: Nordic walking was effective for the elderly with a high risk of depression. Therefore, Nordic walking may be an option for preventing elderly mental disorders and functional improvement.

Key Words: Nordic walking, Depression, Balance, Muscle strength

\section{Introduction}

Korea has entered a fast aging society, and as of 2020, the population over 65 years old is 8.12 million, accounting for $15.7 \%$ of the total population. Approximately $46.5 \%$ of the total population is expected to be over 65 years of age by 2067 . Hence, the psychological and physical 
problems of the elderly due to aging are emerging in various fields of society [4].

Deterioration of physical function and visual deficits, such as glaucoma due to aging, cause limitations in the basic activity of daily living performance, psychological problems [5] and gait disorders, which include a slow pace, broad base, and shuffling [6]. In particular, deficits of visual function, such as glaucoma, induce stereoacuity in the visual acuity. This may also induce gait disorders [7]. Muscle strength and balance are the most commonly studied impairments in mobility limitations, such as gait disorder [8]. Rantanen et al. [9] reported an association between the lower extremity muscle strength and selfreported mobility difficulties, such as walking outdoors. Sallinen et al. [10] suggested that the handgrip strength thresholds determine the likelihood of mobility. Physical balance problems with aging lead to a high risk of falls. The elderly have slow environment adaptation and insufficient body stability, increasing the risk of falls [6].

Therefore, maintaining muscle strength, such as handgrip, lower extremity muscle strength, and balance, is very important for the mobility and functional independence in the elderly.

According to the survey on the actual conditions of older people in Korea in 2017, 21.1\% of those older than 65 years who experience depression [2], which can induce cognitive decline and reduced quality of life $[11,12]$.

Depression should be managed early because it can increase the likelihood of death, suicide, or psychological disease, such as dementia [13]. One of the major factors in preventing depression is physical activity $[14,15]$. Physical activity not only prevents depression [16] but also prevents various diseases by improving blood pressure or diseases related to fat in the body and increasing the ability to control blood sugar [17]. In addition, constant management is necessary because physical activity can increase interest in health promotion, such as diet control, smoking cessation, and stress management, and improve the quality of life $[18,19]$.

Although there are limitations to the exercise that the elderly can perform directly, walking exercise can be performed safely by the elderly because it is simple and easy to practice, and there is less risk of injury than with other exercises. If the elderly continue to perform walking exercise, it improves blood circulation and increases blood flow to the brain, which would be helpful for improving the cognitive function [20]. Supervised resistance walking exercise improves the physical function significantly in older people [21].

Although walking has many beneficial effects, the effects of walking on mood, such as depression, are unclear and vary from researcher to researcher. Some studies reported that walking helped decrease the depression of the elderly [22,23]. Others reported that walking exercise did not show the effect of mood [24]. Therefore, considering the impact of depression, it is unclear if walking would be sufficient to improve the depression for the elderly.

The walking exercise method varies according to the intensity and characteristics of the walking pattern, such as general walking, power walking, Nordic walking, and Masai walking. Among these walking methods, Nordic walking shows greater and faster benefits than general walking [25]. Meta-analysis has shown that Nordic walking provides a safe and effective way to improve the physical functions, such as blood pressure, exercise capacity, and maximal oxygen consumption in the elderly due to the use of a pole $[26,27]$. Furthermore, Nordic walking can be used to treat stress and depression by regulating the beta-endorphin hormone in the brain by naturally receiving sunlight outdoors and improving physical function using a stick [28]. Most studies on Nordic walking have researched obesity, diabetes mellitus, or artery disease [26]. There has been little research on the effects of Nordic walking on the depression of the elderly.

Therefore, this study examined the effects of a prolonged period (12 weeks) of Nordic walking and general leisure 
program in the elderly with a high risk of depression. Nordic walking was expected to have more benefits on depression and physical function.

\section{Method}

\section{Participants}

Forty elderly participants aged 65 or older were recruited from S senior care facility in Gyeonggi-do. The sample size was calculated with G-power based on Lee and Park [29], which revealed a sample size of 18 (effect size: 1.87, Power $.95, a=.05$ ). Forty subjects were recruited, considering a 50\% drop rate. Twenty subjects were assigned randomly to the Nordic walking group and the general leisure group as a control group. All subjects were selected according to the inclusion and exclusion criteria. The inclusion criteria for participants were as follows: (1) older people who have recently been diagnosed with depression (within three months) from a psychiatrist and were taking drugs for it, (2) elderly who received a greater than 18 score on the elderly depression test from a welfare center counselor. On the other hand, those who had difficulty participating in the exercise due to severe diseases (e.g., severe arthritis and osteoporosis) were excluded. Eight subjects, three in the Nordic walking group and five in the control group, dropped out for personal reasons, such as did not participate in the final evaluation or disease. Before the participants started the program, all were informed of the study's aims and procedures and signed informed consent forms. This study conformed to the ethical principles of the Declaration of Helsinki. Table 1 lists the general characteristics of the subjects.

\section{Measurement Tool}

\section{1) Depression Test}

The Geriatric Depression Scale (GDS) comprises 30 simple questions and is a screening test for depression for the elderly [30]. This study used the Revised Korean version of the Geriatric Depression Scale (GDS-KR). The test-retest reliability was .90 [31].

\section{2) Muscle Strength Test}

The muscle strength of the participants was examined using the grip strength and 30-second Sit to Stand (STS) test. The grip strength test, which tends to decrease with age or through lack of activity, is most commonly used to predict the changes in muscle strength, and the reliability is high at .81 [32]. First, the subjects stand with their feet shoulder-width apart and arms dropped along the side. The dynamometer is aligned with the second finger of the subject. The subject holds the dynamometer in their hand, and they then exert their maximum strength. The tester records a high value $(\mathrm{kg})$ by measuring the right and left hands twice [33].

The 30 second Sit to Stand (STS) is used to measure the muscle strength of the lower extremity. The tester counts the number of times the elderly can perform the stand-up test for 30 seconds. First, the subject sits on a chair with their backs straight, feet flat on the floor, and hands crossed. Next, the subject raises to a full standing position and then sits back down on the chair. The subject repeats this posture

Table 1. General Characteristics of the Participants

\begin{tabular}{ccc}
\hline & Nordic Group & Control Group \\
\hline Sex (Male / Female) & $2 / 15$ & $3 / 12$ \\
Age (years) & 75.24 & 76.73 \\
Height $(\mathrm{cm})$ & 149.2 & 56.2 \\
Weight $(\mathrm{kg})$ & 148.8 & 57.3 \\
\hline
\end{tabular}


Table 2. Nordic Program

\begin{tabular}{cccc}
\hline Exercise Phases & Exercise Form & Exercise Time (min) & Exercise Frequency \\
\hline Warming Up & Stretching & 5 min & - \\
\hline \multirow{2}{*}{ Main Exercise } & A Course (Including Flatland Park) & 50 min & $\begin{array}{c}\text { Earlier Six Weeks } \\
/ \text { Twice a Week } \\
\end{array}$ \\
& B Course (Including Uphill, Downhill, and Flat Park) & 50 min & $\begin{array}{c}\text { Later Six Weeks } \\
/ \text { Twice a Week }\end{array}$ \\
\hline Final Exercise & Stretching & 5 min & - \\
\hline
\end{tabular}

for 30 seconds. The test discounts the number if they cannot maintain the posture [34]. The test has a test-retest inter-rater reliability of .987 [34].

\section{3) Balance Test}

A Functional Reach Test (FRT) and One Leg Standing Balance test were used to examine the balance of the subject. FRT is a clinically accepted tool to measure the balance of the elderly and subjects with neurological disorders [35]. The participants were instructed to stand with their feet shoulder-width apart, and their shoulders flexed $90^{\circ}$. The test recorded the starting position with a reference of the third metacarpal head. The participants performed their trunk as forward as possible without moving their position. At this point, the tester recorded the position of the third metacarpal head. The difference in centimeters between the two positions was the value. The test was performed three times, with the average taken.

The one-leg standing (OLS) test is the balance test, which is a simple, predictive, and inexpensive marker helpful in clinics [36]. The participants were instructed to stand on one leg without support with their eyes open. The number of seconds was recorded if the elderly patient could not maintain this position [37]. The reliability of the OLS Test showed good intraclass correlations coefficients (ICC range $=.95$ to .099 ). The within raters ICC ranged from .73 to $.93[37,38]$.

\section{Procedure}

This program was carried out for 12 weeks from September to December 2019. The same tester performed the pre-and post-tests in the Nordic walking program and control groups to ensure consistency. The tests included depression (GDS-KR), muscle strength test (grip strength and 30 second STS), and balance test (FRT, OLS).

For the Nordic walking program, Nordic walking was conducted for $60 \mathrm{~min}$, two times per week, for 12 weeks. During the first six weeks, subjects walked at a medium tempo and medium strength in a $4 \mathrm{~km}$ flat park near a streamside. In the next six weeks, they walked at the same tempo in a $5 \mathrm{~km}$ with uphill, downhill, and flat areas (Table 2). The leisure group as the control selected only one class among calligraphy, singing classes, and playing. They performed the selected leisure program for $60 \mathrm{~min}$, two times per week, for 12 weeks.

\section{Statistical Analysis}

The descriptive statistics were analyzed using their mean and standard deviation. To determine the effects of the program, the Wilcoxon signed-rank test was used to compare the pre- and post-program. The Mann-Whitney $\mathrm{U}$ test was used to compare all the variables between the two groups. The assumption of normality was ascertained before using the Shapiro-Wilk tests, and none of the items had a normal distribution. Therefore, a non-parametric analysis was used. Statistical analysis was conducted using the SPSS (IBM, Korea) version. 20.0, and the significance 
Table 3. Effect of the Nordic Walking Group $(n=17)$

mean $\pm S D$

\begin{tabular}{|c|c|c|c|c|}
\hline \multicolumn{2}{|c|}{ Items (unit) } & \multirow{2}{*}{$\begin{array}{c}\text { Pre } \\
23.00 \pm 3.30\end{array}$} & \multirow{2}{*}{$\begin{array}{c}\text { Post } \\
19.47 \pm 2.79\end{array}$} & \multirow{2}{*}{$\frac{\mathrm{p}}{.000^{*}}$} \\
\hline Depression (score) & & & & \\
\hline \multirow{3}{*}{ Muscle Strength } & Grip Lt (kg) & $20.65 \pm 4.23$ & $23.33 \pm 5.28$ & $.001 *$ \\
\hline & Grip Rt (kg) & $22.21 \pm 4.72$ & $24.11 \pm 5.35$ & $.030^{*}$ \\
\hline & $30 \mathrm{sec}$ STS (number) & $14.06 \pm 4.64$ & $20.53 \pm 5.57$ & $.000^{*}$ \\
\hline \multirow{3}{*}{ Balance } & FRT $(\mathrm{cm})$ & $22.10 \pm 7.05$ & $24.88 \pm 6.20$ & $.019^{*}$ \\
\hline & One Leg Stand Lt (sec) & $35.25 \pm 43.99$ & $42.72 \pm 43.43$ & $.019^{*}$ \\
\hline & One Leg Stand Rt (sec) & $32.71 \pm 40.51$ & $46.41 \pm 53.39$ & $.001^{*}$ \\
\hline
\end{tabular}

SD: Standard Deviation, ${ }^{*} \mathrm{p}<.05$

Table 4. Effect of General Leisure Group $(n=15)$

mean $\pm S D$

\begin{tabular}{ccccc}
\hline \multicolumn{2}{c}{ Items (unit) } & Pre & Post & p \\
\hline \multirow{2}{*}{ Depression (score) } & & $21.33 \pm 3.24$ & $21.87 \pm 2.85$ & .351 \\
\hline \multirow{3}{*}{ Muscle Strength } & Grip Lt (kg) & $21.47 \pm 7.53$ & $20.58 \pm 7.51$ & $.023^{*}$ \\
& Grip Rt (kg) & $23.40 \pm 7.47$ & $22.46 \pm 7.47$ & .060 \\
\hline \multirow{2}{*}{ Balance } & 30 sec STS (number) & $14.87 \pm 5.51$ & $14.77 \pm 5.39$ & .531 \\
& FRT (cm) & $21.85 \pm 7.55$ & $20.97 \pm 7.39$ & $.014^{*}$ \\
& One Leg Stand Lt (sec) & $30.75 \pm 40.12$ & $21.37 \pm 23.20$ & .053 \\
& One Leg Stand Rt (sec) & $28.92 \pm 42.04$ & $22.91 \pm 22.87$ & .191 \\
\hline
\end{tabular}

SD: Standard Deviation, ${ }^{*} \mathrm{p}<.05$

was accepted for values of $a=.05$.

\section{Results}

\section{Depression}

Looking at the depression score, the Nordic walking group decreased from 23 to 19.4, showing a significant difference between pre and post. (Table 3) On the other hand, the depression score in the control group did not change between pre and post (Table 4).

The change in depression after Nordic walking decreased by 3.53 , showing improvement compared to the control group. In the case of grip strength, the change in the Nordic walking group increased by 2.68 (LT: left) and 1.90 (RT: right), but the control group decreased by -.88 (LT) and -.94 (RT). The $30 \mathrm{sec}$ STS increased by 6.47 in the Nordic walking group but decreased by -.09 in the control group (Table 5).

\section{Muscle Strength}

The grip strength of the right and left increased from 22.20 to 24.11 in the Nordic walking group, showing a significant difference between the pre and post-test. (Table 3) In contrast, both grip strengths decreased in the control group. (Table 4) The $30 \mathrm{sec}$ STS that means the strength of the lower extremity increased from 14.06 to 20.53 in the Nordic walking group, showing a significant difference between pre and post-test, but there was no change in the control group.

Regarding the change in grip strength, the Nordic walking group increased by 2.68 (RT) and 1.91(LT), and there was a significant difference between the groups. In 
Table 5. Comparison of the Change between the Nordic Program Group and the General Leisure Group $(n=32)$

mean $\pm \mathrm{SD}$

\begin{tabular}{|c|c|c|c|c|}
\hline \multicolumn{2}{|c|}{ Items (unit) } & Nordic Program Walking & General Leisure & $\mathrm{p}$ \\
\hline \multicolumn{2}{|l|}{ Depression (score) } & $-3.53 \pm 2.13$ & $.53 \pm 1.81$ & $.000^{*}$ \\
\hline \multirow{3}{*}{ Muscle Strength } & Grip Lt (kg) & $2.68 \pm 2.91$ & $-.89 \pm 1.21$ & $.007 *$ \\
\hline & Grip Rt (kg) & $1.91 \pm 3.22$ & $-.94 \pm 1.72$ & $.000^{*}$ \\
\hline & $30 \mathrm{sec}$ STS (number) & $6.47 \pm 3.22$ & $-.09 \pm 2.20$ & $.000^{*}$ \\
\hline \multirow{3}{*}{ Balance } & FRT $(\mathrm{cm})$ & $2.78 \pm 4.68$ & $-.87 \pm 1.16$ & $.002 *$ \\
\hline & One Leg Stand Lt (sec) & $7.47 \pm 10.31$ & $-9.38 \pm 20.84$ & $.001 *$ \\
\hline & One Leg Stand Rt (sec) & $13.70 \pm 29.79$ & $-6.00 \pm 39.77$ & $.001 *$ \\
\hline
\end{tabular}

SD: Standard Deviation, ${ }^{*} \mathrm{p}<.05$

the $30 \mathrm{sec}$ STS case, the Nordic walking group showed improvement, with the number of lifts increasing by 6.47 . In contrast, the general leisure group showed a similar score after the program, with the number of lifts increasing by .09 (Table 5).

\section{Balance}

The score of FRT increased from 22.1 to 24.8, and the OLS increased from 35(LT) and 32(RT) to 42.72(LT) and 46.40(RT), respectively, in the Nordic walking group. (Table 3) In the control group, however, the FRT decreased from 21.8 to 20.9, and the OLS decreased from 30.74(LT) and 28.91(RT) to 21.36(LT) and 22.91(RT) (Table 4).

The Nordic walking group showed high improvement in the right OLS test. In the control group, the left and right OLS showed a high decline. The FRT increased by 2.77 in the Nordic walking group, but it decreased by -.873 in the control group. The OLS increased by 7.47 (left) and 13.69 (right) in the Nordic walking program, but decreased by -9.38 (left) and -6.03 (right) in the control group (Table 5).

\section{Discussion}

This study examined the effects of Nordic walking on the depression and physical function improvement in the elderly. Nordic walking affected improved depression and physical function in the elderly.

Most elderly people experience depression. In particular, elderly women, widowed, and elderly living alone are diagnosed with depression or feel depression relatively faster [39]. The symptoms of depression in the elderly can be overlooked easily because they show common symptoms, such as indifference, lethargy, and sleep problems. Therefore, careful observations and various approaches at the community level are required.

To date, in addition to medication, recall therapy, exercise, and supportive contact have been developed to treat depression in the elderly [40]. Exercise promotes the release of serotonin [40] and $\beta$-endorphins and increases the core body temperature in areas, such as the brain stem, which can lead to a decrease in depression [42]. Specifically, aerobic exercise has more efficacy in the treatment of depression [43]. Aerobic exercise with a bright light has a more positive effect on serotonin secretion [44]. Nordic walking is an aerobic exercise and outdoor activity receiving sunlight. Therefore, Nordic walking might be effective in decreasing depression.

Depression causes sleep disturbances that are related to the change in melatonin in the circadian rhythm [45]. Sleep disturbances, such as insomnia and hypersomnia, are important symptoms of mood disorders and are some of 
the criteria for diagnosing major depressive disorder and bipolar mood disorder [1]. Thus, researchers have been paid attention to melatonin secretion because it plays an important role in sleep to treat depression.

Melatonin secretion is related to stabilizing sleep, schizophrenia or fibromyalgia, and seasonal depression disorder. Therefore, various attempts have been made to treat the disease with melatonin. One of the treatments is using light, such as sunlight [46]. Furthermore, serotonin deficiency is associated with depression, sleep disturbance, and anxiety [47]. A combination of exercise and sunlight positively affects serotonin expression in the brain [44]. In other words, a combination of sunlight and exercise will be very helpful in treating depression because it helps with melatonin secretion and serotonin secretion

In this study, the Nordic Walking Group conducted exercise outdoors for 50 minutes, twice a week, mostly in places with relatively little shade, such as around rivers and low mountains with uphill slopes. Most of the participants were exposed to sunlight, which is why there was a significant decrease in the depression score after the Nordic walking compared to the control group. This result is consistent with Suija et al. [48] and Lee and Park [29]. In contrast, Kim et al. reported that a walking program did not improve the mood state, such as depression, in women with obesity.

This difference may be due to the characteristics of the subjects and exercise methods of study. Kim's study targeted subjects recruited from general health check-ups, but the subjects in this study were the elderly with a risk of depression. This study conducted a group exercise with a physical therapist as supervisor. In contrast, Kim's study was performed as a self-exercise that consisted of recording individual self-exercise and checking it with a telephone call. Therefore, Kim's research was not a combination of exercise and sunlight.

The decline in gait performance with aging is related to a high risk of morbidity and mortality, more hospitalizations, and a poorer quality of life [49,50]. A slower walking velocity is associated with an increased risk of dementia and is used to predict dementia [51]. The decline of gait performance is strongly associated with the muscle strength of the lower extremity [52] and balance with sarcopenia due to aging. Moderate to high-intensity exercise improves muscle strength and balance [53]. Therefore, this study examined whether the strength and balance ability, which are the abilities necessary for the elderly who require independence, can be increased by Nordic walking.

In this study, there was a significant increase in grip strength and lower extremity muscle strength after applying Nordic walking compared to the control group. Ossowski et al. [54], Mullo et al. [25], and Lee and Park [29] reported similar effects of Nordic walking on the leg strength. Nordic walking is an aerobic exercise that can lead to an increase in muscle strength [25]. On the other hand, the process of learning the Nordic walking technique might stimulate the neuromuscular component. Indeed, with Nordic walking, factors, such as posture, which gives strength to the upper limb by holding a stick, the effort to maintain the correct posture during the cross movement of the upper and lower limbs, and walking uphill help improve the upper and lower limb muscle strength.

In the balance ability, including FRT and OLS test, the Nordic walking group showed significant improvement compared to the control group because it helped maintain a stable posture by adapting itself to dynamic changes in the movement of using a stick while walking.

There are limitations in applying moderate or higher exercise to the elderly. When the elderly participate in an exercise program, their age, various chronic diseases, decline in physical function, and potential safety accidents during the program should be considered. In contrast, Nordic walking can adjust the difficulty level considering the health condition of the elderly. The use of a pole activates the movement of the upper body to assist in stable 
walking, thereby minimizing the risk of safety accidents such as falls. The results of this study show that Nordic walking is a moderate exercise that can be applied to improve the physical function of the elderly.

The limitation of this study was the small sample size available to participate in the program. Therefore, there are limitation of generalization of results. Second, this study did not control the eating habits, which can influence the health condition of the elderly. Third, the subjects who participated in this study were instructed in the program two times per week. Other activities in daily living were not controlled, which might have affected the results. Overall, these limitations may have affected the interpretation of the results.

\section{Conclusion}

As a result of conduction in the Nordic walking program for 12 weeks, the elderly with a high risk of depression demonstrate improvement in the depression score, muscle strength, and balance. Therefore, Nordic walking may be an attractive option for improving the depression and physical function of the elderly. Future studies will be needed to help prevent dementia, obesity, sleep disorders through Nordic walking.

\section{References}

[1] Association AP. Diagnostic and statistical manual of mental disorders (DSM-5®). American Psychiatric Pub. 2013.

[2] Jeong $\mathrm{KH}, \mathrm{Oh} \mathrm{YH}, \mathrm{EN} \mathrm{K}$, et al. The survey on the actual conditions of older person in Korea. . In: Welfare; MoHa. Sejong. Korean. 2017.

[3] KOSIS: http://kosis.kr/statHtml/statHtml.do?orgId=101 \&tblId=DT_1BPA002\&conn_path=, 2020.

[4] Kim KH. Welfare for the elderly in an aging society with low birth rates. Social Research 2004;5(1):27-52.

[5] Chun MU, Choi JW, Kang SG, et al. The Relationship between Health Related Physical Fitness, Depression, and Quality of Life of the Elderly JKCS. 2019;10(12): 387-97.

[6] Cruz-Jimenez M. Normal Changes in Gait and Mobility Problems in the Elderly. Phys Med Rehabil Clin N Am. 2017;28(4):713-25.

[7] Choi JH, Lee KJ. The change of binocular visual function in mild. moderate and severe glaucoma patients. Korean J Vis Sci.17(3):300-8.

[8] Rantakokko M, Mänty M, Rantanen T. Mobility decline in old age. Exercise and Sport Sciences Reviews. 2013;41(1):19-25.

[9] RANTANEN T, ERA P, HEIKKINEN E. Maximal Isometric Strength and Mobility among 75-year-old Men and Women. Age and Ageing. 1994;23(2):132-7.

[10] Sallinen J, Stenholm S, Rantanen T, et al. Hand-Grip Strength Cut Points to Screen Older Persons at Risk for Mobility Limitation. 2010;58(9):1721-6.

[11] Ha MS, Park RJ. A Study of Cognitive Function and Depression of the Elderly in a Institution. Journal of The Korean Society of Physical Medicine. 2008;3(4): 285-92.

[12] Joshi S, Mooney SJ, Kennedy GJ, et al. Beyond METs: types of physical activity and depression among older adults. Age and Ageing. 2016;45(1):103-9.

[13] WHO: Mental health of older adults. Available at https://www.who.int/news-room/fact-sheets/detail/ment al-health-ofolder-adults, accessed on August 14, 2019.

[14] You KU, Won YB. The Correlation between Physical Activity, Negative Emotion, Economic Level and Mental Health Condition of Elderly People Korean Journal of Sport Psychology. 2010;21(4):197-205.

[15] Lee H, Lee JA, Brar JS, et al. Physical activity and depressive symptoms in older adults. 2014;35(1): 37-41.

[16] Kim Bj. Factors Influencing Depressive Symptoms in the Elderly: Using the 7th Korea National Health and Nutrition Examination Survey (KNHANES VII-1). J Health Info Stat 2020;45(2):165-72. 
[17] Jung SR, Kim WS. Exercise Intervention on Blood Glucose Control of Type 2 Diabetes with Obesity : A Systematic Review. J Korean Soc Phys Med. 2018;13(1):11-26.

[18] Lee BH, Park JS, Kim NR. The Effect of Physical Activity Program on Cognitive Function, Physical Performance, Gait, Quality of Life and Depression in the Elderly with Dementia Journal of Special Education \& Rehabilitation Science. 2011;50(2):307-28.

[19] Golinowska S, Groot W, Baji P, et al. Health promotion targeting older people. BMC Health Services Research. 2016;16(5):345.

[20] Kim YG, Han DW, Lee BK. The Effects of Walking and Yoga Exercise on the Cognitive Functions in the Elderly Women. KSPM. 2010;5(2):211-21.

[21] Chase J-AD, Phillips LJ, Brown M. Physical Activity Intervention Effects on Physical Function Among Community-Dwelling Older Adults: A Systematic Review and Meta-Analysis. Journal of aging and physical activity. 2017;25(1):149-70.

[22] Kim DH, Suh YS, Lee DH. The Effect of the 12 Weeks Walking Program on Walking Posture and Mood of Community Elderly. KJCG. 2007;8(4):419-26.

[23] Huh YG, Jung WS, Lee MG. Effects of a 13-week outdoor group walking exercise on depression and its related variables in elderly women. Korean Journal of Sports Science. 2014;23(2):1351-64.

[24] Kim CS, Kang SY, Nam JS, et al. The Effects of Walking Exercise Program on BMI, Percentage of Body Fat and Mood State for Women with Obesity. KOSSO. 2004;5(2): 223-32.

[25] Muollo V, Rossi AP, Milanese C, et al. The effects of exercise and diet program in overweight people - Nordic walking versus walking. Clin Interv Aging. 2019;14: 1555-65.

[26] Tschentscher M, Niederseer D, Niebauer J. Health benefits of Nordic walking: a systematic review. Am J Prev Med. 2013;44(1):76-84.

[27] Skórkowska-Telichowska K, Kropielnicka K, Bulińska
$\mathrm{K}$, et al. Nordic walking in the second half of life. Aging Clin Exp Res. 2016;28(6):1035-46.

[28] Suija K, Pechter U, Kalda R, et al. Physical activity of depressed patients and their motivation to exercise: Nordic Walking in family practice. Int J Rehabil Res. 2009;32(2):132-8.

[29] Lee HS, Park JH. Effects of Nordic walking on physical functions and depression in frail people aged 70 years and above. Journal of Physical Therapy Science. 2015; 27(8):2453-6.

[30] Yesavage JA, Brink TL, Rose TL, et al. Development and validation of a geriatric depression screening scale: a preliminary report. J Psychiatr Res. 1982;17(1):37-49.

[31] Kim JY, Park JH, Lee JJ, et al. Standardization of the korean version of the geriatric depression scale: reliability, validity, and factor structure. Psychiatry investigation. 2008;5(4):232-8.

[32] Wolinsky FD, Miller DK, Andresen EM, et al. Further Evidence for the Importance of Subclinical Functional Limitation and Subclinical Disability Assessment in Gerontology and Geriatrics. The Journals of Gerontology: Series B. 2005;60(3):S146-S51.

[33] Lee HS, Lee CH. The Effect of Progressive Resistance Training with Elastic Band on Grip Strength and Balance in Middle Elderly Women. JKPT. 2013;25(2):110-6.

[34] Madhushri P, Dzhagaryan A, Jovanov E, et al. An mHealth Tool Suite for Mobility Assessment. Information. 2016; 7(3).

[35] DeWaard BP, Bentrup BR, Hollman JH, et al. Relationship of the Functional Reach and Lateral Reach Tests in Elderly Females. Journal of Geriatric Physical Therapy. 2002; 25(3):4-9.

[36] Vellas BJ, Rubenstein LZ, Ousset PJ, et al. One-leg standing balance and functional status in a population of 512 community-living elderly persons. Aging (Milano). 1997;9(1-2):95-8.

[37] Briggs RC, Gossman MR, Birch R, et al. Balance Performance Among Noninstitutionalized Elderly 
Women. Physical Therapy. 1989;69(9):748-56.

[38] Franchignoni F, Tesio L, Martino MT, et al. Reliability of four simple, quantitative tests of balance and mobility in healthy elderly females. Aging Clinical and Experimental Research. 1998;10(1):26-31.

[39] Lee SJ, Yun GH, Lee JY, et al. Factors Influencing Period from Retirement to Occurrence of Depression of Elderlies. The Journal of Humanities and Social science 2017; 8(5):905-26.

[40] Chung HA. A Literature Review a Program of Intervention of patient Geriatric Depression The Journal of Occupational Therapy for the Aged and Dementia 2008;2(1):59-67.

[41] Wipfli B, Landers D, Nagoshi C, et al. An examination of serotonin and psychological variables in the relationship between exercise and mental health. 2011;21(3):474-81.

[42] Craft LL, Perna FM. The Benefits of Exercise for the Clinically Depressed. Primary care companion to the Journal of clinical psychiatry. 2004;6(3):104-11.

[43] Silveira H, Moraes H, Oliveira N, et al. Physical Exercise and Clinically Depressed Patients: A Systematic Review and Meta-Analysis. Neuropsychobiology. 2013;67(2): 61-8.

[44] Sung JK, Song KS, Kwon SO. Effects of Treadmill Exercise and Bright Lighton Serotonin Expression in Rat Brain. Korean Journal of Sport Science 2014;25(2): 193-201.

[45] Lee JS, Kim SG, Kim JH, et al. Melatonin in Psychiatric Disorders. Sleep Medicine and Psychophysiology. 2015;22(1):5-10.

[46] Kim MG, Park SK, Ahn SCJJoLS. Rhythmic control and physiological functional significance of melatonin production in circadian rhythm. 2013;23(8):1064-72.

[47] Neumeister A, Young T, Stastny JJP. Implications of genetic research on the role of the serotonin in depression: emphasis on the serotonin type $1 \mathrm{~A}$ receptor and the serotonin transporter. 2004;174(4):512-24.

[48] Suija K, Pechter Ü, Kalda R, et al. Physical activity of depressed patients and their motivation to exercise: Nordic Walking in family practice. 2009;32(2):132-8.

[49] Hirvensalo M, Rantanen T, Heikkinen E. Mobility difficulties and physical activity as predictors of mortality and loss of independence in the community-living older population. J Am Geriatr Soc. 2000;48(5):493-8.

[50] Verghese J, LeValley A, Hall CB, et al. Epidemiology of gait disorders in community-residing older adults. Journal of the American Geriatrics Society. 2006;54(2): 255-61.

[51] Lee HS, Park SW. Assessment of gait as a diagnostic tool for patients with dementia. JKSoPM. 2017;12(2): 129-36.

[52] Ko SU, Stenholm S, Metter EJ, et al. Age-associated gait patterns and the role of lower extremity strength - results from the Baltimore Longitudinal Study of Aging. Archives of gerontology and geriatrics. 2012;55(2):474-9.

[53] Ahn NY, Kim KJ. Strengthening Exercise for Prevention of Sarcopenia during the Aging Process. J Korean Journal of Obesity. 2012;21(4).

[54] Ossowski ZM, Skrobot W, Aschenbrenner P, et al. Effects of short-term Nordic walking training on sarcopeniarelated parameters in women with low bone mass: a preliminary study. Clin Interv Aging. 2016;11:1763-71. 